\title{
Decision Making and Fertility Preservation in Cancer Patients
}

\author{
Samira Vesali* \\ Department of Epidemiology and Reproductive Health, Royan Institute for Reproductive Biomedicine, Iran
}

Submission: September 3, 2019; Published: September 16, 2019

*Corresponding author: Samira Vesali, Department of Epidemiology and Reproductive Health, Royan Institute for Reproductive Biomedicine, Tehran, Iran

Keywords: Fertility Preservation, Cancer Patients, Childbearing capacity, Oncologists, Pediatric cancer patients, Psychological counseling, Malpractice and decisional conflict, Biological children, Cancer progression, Fertility specialist

Abbreviations: FP: Fertility preservation; ASCO: American Society for Clinical Oncology

\section{Opinion}

Infertility following cancer treatment in cancer patients is consequently a source of psychosocial and emotional distress and may severely impact quality of life into survivorship [1,2]. Therefore, storing the potential or material to have biological children after cancer treatment can be of high importance to many cancer survivors and help them adjust to life after cancer therapy [3]. There are various fertility preservation (FP) techniques with the aim of saving the possibility of childbearing capacity in prepubertal and pubertal cancer patients [4]. It is important that patients are adequately supported to determine which options are best suited to their individual situation [5]. Decisions surrounding FP in children, adolescents, and adults can be difficult due to the distress of a cancer diagnosis, time constraints for decision-making, and lack of efficacy data, oncological treatment planning and preparation, and possible fertility treatment financial barriers, etc. [6,7]. Given the nature of the multi-step decision-making process, the key question is who decides to preserve fertility in cancer patients; oncologists, reproductive specialists, embryologists, other health care providers, or the patient. American Society for Clinical Oncology (ASCO) outlines "oncologists should address the possibility of infertility with patients treated during their reproductive years and be prepared to discuss possible FP options or refer appropriate and interested patients to reproductive specialists" [8]. Therefore, the potential risk should be discussed with all pubertal or post-pubertal patients at the time of diagnosis. It has been suggested that the discussion should include an explanation of potential methods of FP [9]. Given the recommendation, all health care providers and physicians involved in the FP process in cancer patients are only responsible for keeping the patient fully and comprehensively informed and referring the patient to a fertility specialist. It is up to the patient to make the decision to use FP.

Regarding pediatric cancer patients, parents make decisions about the use of FP in their children. However, in some societies, especially less developed countries with poor referral systems, oncologists proceed to make decisions about introduce and use of FP in their patients. The majority of them believe that the patients are not fully aware of the complexity, prognosis or recurrence of their illness, and lack the competence to make final decisions. On the other hand, some of the physicians minimize any possible delay in cancer treatment of some patients, because interruption of treatment due to use of FP may lead to cancer progression. Time and timing are also likely to be important. According to the ASCO guideline, clinicians should not censor fertility related information to prevent any perceived additional burdens. The valuable point is that some of them disagree with medical malpractice due to lack of giving accurate information to patients and depriving them of childbearing. Lack of supervision over oncologists' functioning is the weakness of the care system in these countries. In that case, disappointment dominates on patients, especially adult and young adolescence, may consider end-of-life and even attempt to commit legal euthanasia. Preserving fertility and storing the potential or material to have biological children after cancer treatment can be hopeful for patients and improve their quality of life. In the absence of literature, it can only be suggested to reduce such malpractice and decisional conflict and regret about FP use, especially between parents, a consultant is required to participate in the patient's decision-making process. In the other, after given adequate information about FP services and referring to equipped centers providing FP by the oncologist, the consultant 


\section{Global Journal of Reproductive Medicine}

will be able to discuss the patients or parents to justify them to use FP and adjust to life after cancer therapy through minimizing psychosocial and emotional distress. In the global oncology guidelines, it is felt that there is a need for consultation in the decision-making process on FP use in the patients. Prior to this, the role of psychological counseling in making the right decisions about saving fertility must be confirmed in various studies.

\section{References}

1. Letourneau JM (2012) Pretreatment fertility counseling and fertility preservation improve quality of life in reproductive age women with cancer. Cancer 118 (6): 1710-1717.

2. Logan S (2018) Clinician provision of oncofertility support in cancer patients of a reproductive age: A systematic review. Psycho oncology 27(3): 748-756

3. Tschudin S, J Bitzer (2009) Psychological aspects of fertility preservation in men and women affected by cancer and other lifethreatening diseases. Hum Reprod Update 15(5): 587-597.
4. Reis N, NK Beji, A Coskun (2010) Quality of life and sexual functioning in gynecological cancer patients: results from quantitative and qualitative data. Eur J Oncol Nurs 14(2): 137-146.

5. Wang Y, Anazodo A, Logan S (2019) Systematic review of fertility preservation patient decision aids for cancer patients. Psycho oncology 28(3): 459-467.

6. Gardino SL, LL Emanuel (2010) Choosing life when facing death: understanding fertility preservation decision-making for cancer patients. Cancer Treat Res 156: 447-458.

7. Kim J (2013) Fertility preservation consultation for women with cancer: are we helping patients make high-quality decisions. Reprod Biomed Online 27(1): 96-103.

8. Lee SJ, Schover LR, Partridge AH, Patrizio P, Wallace WH (2006) American Society of Clinical Oncology recommendations on fertility preservation in cancer patients. J Clin Oncol 24(18): 2917-2931.

9. Yeomanson DJ, S Morgan, AA Pacey (2013) Discussing fertility preservation at the time of cancer diagnosis: dissatisfaction of young females. Pediatr Blood Cancer 60(12): 1996-2000.

Your next submission with Juniper Publishers
will reach you the below assets
- Quality Editorial service
- Swift Peer Review
- Reprints availability
- E-prints Service
- Manuscript Podcast for convenient understanding
- Global attainment for your research
- Manuscript accessibility in different formats
( Pdf, E-pub, Full Text, Audio)
- Unceasing customer service
Track the below URL for one-step submission
https://juniperpublishers.com/online-submission.php

